\title{
PREDICTORS OF SERUM POLYCHLORINATED BIPHENYL (PCB) CONCENTRATIONS IN ANNISTON RESIDENTS
}

Pavuk $\mathrm{M}^{1}$, Olson $\mathrm{JR}^{2}$, Wattigney $\mathrm{WA}^{1}$, Dutton $\mathrm{ND}^{3}$, Sjödin $\mathrm{A}^{4}$, Shelton $\mathrm{C}^{5}$, Turner $\mathrm{WE}^{4}$, Bartell

$\mathrm{SM}^{6}$ for the Anniston Environmental Health Research Consortium

${ }^{1}$ Agency for Toxic Substances and Disease Registry, Atlanta, GA, USA

${ }^{2}$ School of Medicine and Biomedical Sciences, University at Buffalo, State University of New York, Buffalo, NY, USA

${ }^{3}$ Oak Ridge Institute for Science and Education (ORISE) Research Participant, Agency for Toxic Substances and Disease Registry, Atlanta, GA, USA

${ }^{4}$ National Center for Environmental Health, Centers for Disease Control and Prevention, Atlanta, GA, USA

${ }^{5}$ College of Nursing, Jacksonville State University, Jacksonville, AL, USA

${ }^{6}$ Program in Public Health and Department of Statistics, University of California, Irvine, CA, USA

May 30, 2014

Correspondence:

Marian Pavuk, MD, PhD

Division of Toxicology and Human Health Sciences

Agency for Toxic Substances and Disease Registry

Center for Disease Control and Prevention

4770 Buford Highway, Mail Stop F-57

Atlanta, GA 30341

Phone: 1-770-488-3671

Email: MPavuk@cdc.gov 
Members of the Anniston Environmental Health Research Consortium Steering Committee include S. Carter, community representative; S. Bartell, University of California-Irvine; D.O. Carpenter, University at Albany; J. Cash; R. Foushee and A. Percy, University of AlabamaBirmingham; H. Frumkin, University of Washington; M. Lavender, Center for Domestic Preparedness; K. Moysich, Roswell Park Cancer Institute; J. Olson, University at Buffalo; M. Pavuk, Agency for Toxic Substances and Disease Registry/Centers for Disease Control and Prevention; P. Rosenbaum, A. Silverstone, and R. Weinstock, State University of New York Upstate Medical University; and C. Shelton, Jacksonville State University.

Short title: Predictors of polychlorinated biphenyls

Key Words: Polychlorinated biphenyls, linear regression, Anniston

Acknowledgments: The data used for the present study were collected using a grant from the Agency for Toxic Substances and Disease Registry to Jacksonville State University, \# 5U50TS473215. The contents of this publication are solely the responsibility of the authors and do not necessarily represent ATSDR's or CDC's official views.

This research was supported in part by an appointment to the Research Participation Program at the Centers for Disease Control and Prevention administered by the Oak Ridge Institute for Science and Education through an interagency agreement between the U.S. Department of Energy and CDC/ATSDR.

The authors declare they have no actual or potential competing financial interests.

\section{Abbreviations:}

PCB = polychlorinated biphenyls

ACHS = Anniston Community Health Survey

LOD = limit of detection

$\mathrm{OR}=$ odds ratio

$\mathrm{CI}=$ confidence interval 


\section{Abstract}

The Anniston Community Health Survey is a community-based cross-sectional study of Anniston, Alabama, residents who live in close proximity to a former PCB production facility to identify factors associated with serum PCB levels. The survey comprises 765 Anniston residents who completed a questionnaire interview and provided a blood sample for analysis in 2005-2007. Several reports based on data from the Anniston survey have been previously published, including associations between PCB exposure and diabetes and blood pressure. In this study we examine demographic, behavioral, dietary, and occupational characteristics of Anniston survey participants as predictors of serum PCB concentrations. Participants were 54\% White and 45\% African-American, predominantly female (70\%), with a mean age of 55 years. Linear regression models with stepwise selection were employed to examine factors associated with serum PCBs. Serum PCB concentrations varied widely between participants (range for sum of 35 PCBs: 0.11$170.4 \mathrm{ng} / \mathrm{g}$ wet weight). Statistically significant positive associations were observed between serum PCB concentrations and age, race, residential variables, current smoking, and local fish consumption, as was a negative association with education level. A small age by sex interaction was noted, indicating that the increase in PCB levels with age was steeper for women than for men. Significant interaction terms indicated that the associations between PCB levels and having ever eaten locally raised livestock and local clay were much stronger among African-Americans than among White participants. Age and race were the most influential predictors of serum PCB levels. In summary, demographic variables and past consumption of locally produced foods were found to be 
the most important predictors of PCB concentrations in residents living in the vicinity of a former PCB manufacturing facility. 


\section{Introduction}

Polychlorinated biphenyls (PCBs) are persistent synthetic organochlorine chemicals that were mass-produced in the United States from 1929 to 1977 (ATSDR, 2000a). Starting in 1935, Monsanto Chemical Corporation was the sole US producer (under the trade name "Aroclor") and operated two facilities: one in Sauget, Illinois, and another in Anniston, Alabama. The Anniston plant ceased production in 1971, before the official ban on PCB production in 1977, because of concerns over the toxicity of PCBs and their persistence in the environment (ADPH 1995, 1996; EPA, 1976). Although the levels of PCBs in humans has decreased over time (Longnecker et al., 1997), the potential for exposure to PCBs can continue in some instances because of the presence of products and waste materials containing PCBs in landfills, hazardous waste sites, and contaminated soils and sediments (Nisbet and Sarofim, 1972; ATSDR, 2000b). PCBs accumulate in the food chain (Startin, 1994) and can be detected in virtually all humans (Patterson et al., 2009).

Ingestion of contaminated food products, especially fish and livestock, is often an important pathway of exposure to PCBs (Burns et al., 2009; Hovinga et al., 1992; Humblet et al., 2010; Humphrey and Budd, 1996; Kreiss et al., 1981; Schecter et al., 2001; Sjödin et al., 2000; Startin, 1994). Demographic factors such as age, sex and body mass index (BMI) have also been shown to be important predictors of PCBs in environmentally exposed populations (Agudo et al., 2009; Bräuner et al., 2011; Choi et al., 2006; Garabrant et al., 2009; Laden et al., 1999; Tee et al., 2003). In women, age, alcohol consumption, parity and lactation have been found to be important determinants of PCB concentrations (Rogan et al. 1986; Schwartz et al., 1983). Among young Akwesasne adults (17-21 years old), breastfeeding status, BMI, and consumption of fish in the last year were associated with serum PCBs (Gallo et al., 2011). Occupational 
exposure, mainly from work with capacitors and electrical transformers, is historically an important predictor of PCB levels (Ouw et al., 1976; Seegal et al., 2011; Wolff et al., 1982, 1985). In addition to ingestion of contaminated food products, other routes of exposure, including inhalation and dermal contact, have also been studied (DeCaprio et al., 2005, Löffler and van Bavel, 2000).

Risk factors for non-occupational exposure vary among populations, as the use of PCBs varied by time and geographical location (Nicholson and Landrigan, 1994). Community studies of residents living in proximity to a contaminated site can help elucidate exposure pathways and related socioeconomic or behavioral risk factors (Choi et al, 2006; Fitzgerald et al., 2007).

In addition to the former PCB production facility, the Anniston area also includes two landfills containing PCB waste (capped and closed in early 1980s), as well as several drainage channels and water streams with contaminated sediments. Results of assessments of concentrations of PCBs in soil showed high levels of soil contamination in Anniston decades after PCB production ended (ATSDR, 2000; Orloff et al., 2003). Historical contamination of locally raised hogs, chickens, and other animals was presented during litigation in Anniston (Chemical Industry Archives, 2001; Love, 2007), while contamination of local fish has been thoroughly documented over many years (ADPH, 1995, 1996, 2011). Starting in the 1990s, when Anniston residents brought lawsuits against Monsanto over releases of PCBs into the environment, high concentrations of PCBs began to be documented in some Anniston residents (ADPH, 1996; ATSDR, 2000b; Hansen et al., 2003). 
The Anniston Community Health Survey (ACHS) was a cross-sectional study conducted in 2005-2007 in response to concerns among community members over whether exposure to PCBs had increased their body burden of these contaminants and negatively affected their health. Previous analyses of the ACHS dataset focused on PCB exposure among participants (Pavuk et al., 2014) and on associations of serum PCB concentrations with hypertension and diabetes (Goncharov et al., 2010, 2011; Silverstone et al., 2012). Results from the ACHS analysis of PCB exposure among Anniston residents, with an emphasis on those living near the former production facility, showed that median of the sum of $35 \mathrm{PCB}$ congeners was $528 \mathrm{ng} / \mathrm{g}$ lipid (range: 17.0 to $27,337 \mathrm{ng} / \mathrm{g}$ lipid). In all age groups, the geometric mean concentrations for total PCBs were about two to three times higher for African-American participants than for White participants. When contrasted with similar age and race groups reported from the National Health and Nutrition Examination Survey (NHANES) 2003-2004, serum PCB concentrations in ACHS participants were about three times higher for African-Americans and two times higher for White participants of age 40 and older. For those under age 40, the sum of PCBs for African-American participants was elevated when compared to the NHANES finding, while the sum of PCBs for White participants was similar to the NHANES result. (Pavuk et al., 2009; Patterson et al., 2009; Pavuk et al., 2014).

The goal of the present study was to examine the determinants of PCB exposure in Anniston, focusing on the neighborhood closest to the former PCB production facility. Identification of predictive factors for PCB levels in Anniston residents could form the basis for the development of strategies to limit further exposure in this community. 


\section{Methods}

\subsection{Study population}

The ACHS was designed to examine serum PCB concentrations and health outcomes in residents of Anniston, Alabama, a city of about 24,000 people. Questionnaire data and blood samples were collected in 2005 through 2007. Anniston residents aged 18 years or older were eligible and were selected through a stratified random sample, with oversampling (two-thirds of all eligible) from in west Anniston. Oversampling in west Anniston facilitated enrollment of residents who lived closer to the plant and thus had higher potentials for PCB exposure. A pool of 3,320 eligible addresses was randomly selected from a commercial list of all residential properties in Anniston (2,224 in west Anniston). One adult resident was randomly selected from each of the 1,823 households that were successfully contacted. A survey questionnaire was administered by trained interviewers in participants' homes or a local study office. Fasting blood samples were collected and height and weight were measured at the local study office. All participants provided written informed consent prior to participation. In total, 1,100 residents completed the survey, and 774 volunteered to provide blood samples. Of these, 765 had serum PCB and lipid measurements and were included in the present statistical analyses. The study was reviewed and approved by the Institutional Review Board of the University of Alabama at Birmingham.

A standardized questionnaire was used to collect information on demographics; general and sexspecific health histories; dietary information, including past consumption of meat from locally raised livestock, local fish, home-grown vegetables, and clay; occupational exposures; behaviors 
such as smoking and alcohol consumption; perceptions about environmental PCB contamination and exposure; and litigation knowledge. Participants were asked about consumption of local foods and clay in order to investigate dietary pathways in which the source of PCB contamination is likely to be the Anniston facility and waste sites; eating of non-local foods would be expected to reflect background exposure to PCBs from non-Anniston sources.

\subsection{Assessment of exposure to PCBs and total lipids}

During the office visit, blood samples were collected for serum PCBs ( $2 \mathrm{ml})$ and analyzed by the Centers for Disease Control and Prevention's National Center for Environmental Health laboratory. The laboratory method used to measure serum PCBs has been described previously (Sjödin et al., 2004, Goncharov et al., 2010). Briefly, 33 individual congeners and two pairs of co-eluting congeners were analyzed using high-resolution gas chromatography/isotope dilution high-resolution mass spectrometry (HRGC/IDHRMS). The congeners measured were PCBs 28, $44,49,52,66,74,87,99,101,105,110,118,128,138-158,146,149,151,153,156,157,167$, $170,172,177,178,180,183,187,189,194,195,196-203,199,206$, and 209. Out of 209 possible congeners, these 35 were chosen for analysis because of their relevance in human exposure assessment from multiple exposure pathways and because they represent the majority of steady state and episodic PCB congeners that are selectively found in humans (Hansen, 2001). The sum of the wet weights of these 35 congeners was defined as $\Sigma$ PCBs. Concentrations of individual congeners below the limit of detection were assigned a value equal to the limit of detection (LOD) divided by the square root of 2 (Hornung and Reed, 1990). Individual LODs for each congener and participant, based on sample volume and weight, were used in substitution of 
levels below LOD. When concentrations below LOD were reported by the laboratory, those were included in the dataset and analyses (not imputed) because a reported result, even if below the LOD, remains the best available estimate of the true value (ASTM, 1989).

Serum was also collected to measure triglycerides and cholesterol, which were analyzed at the clinical chemistry laboratory of Jacksonville Medical Center. Total lipids were calculated using an enzymatic "summation" method using triglyceride and total cholesterol measurements, based on the short form equation proposed by Phillips et al. (1989) and updated by Bernert et al. (2007): serum total lipids $=(2.27 *$ total cholesterol $)+$ triglycerides $+62.3 \mathrm{mg} / \mathrm{dl}$.

\subsection{Assessment of covariates}

Predictor variables include age (years), race (African-American, White), sex (female, male), total length of residence in Anniston (years), years at current address, residence in west Anniston (yes, no), educational attainment (high school completion: yes, no), marital status (currently married, not married), current smoking status (yes, no), whether participants drank alcohol in the past 30 days, and annual income (above or below $\$ 20,000$ ). Number of pregnancies, and total months of breastfeeding were used in analyses of women's data; only about $30 \%$ of all women breastfed their infants. Body mass index (BMI) was calculated as $\mathrm{kg} / \mathrm{m}^{2}$ and analyzed as both a continuous and a categorical variable: $<25$ (normal), 25 to $<30$ (overweight) and $\geq 30 \mathrm{~kg} / \mathrm{m}^{2}$ (obese). 
Dietary variables include consumption (ever eaten: yes, no) of locally raised hogs, chicken, or other livestock, local fish (from Snow Creek, Chocolocco Creek, or Lake Logan Martin), local vegetables, and clay. Potential occupational exposures included having ever worked at a job where one might have been exposed to PCBs, transformers, ionizing radiation, pesticides, fertilizers, herbicides, solvents and chemicals/heavy metals such as lead, boron, mercury, or cadmium.

\subsection{Statistical Analysis}

Characteristics of study participants were compared for African-Americans and Whites using a ttest for $\mathrm{\Sigma PCBs}$ and age, analysis of covariance for other continuous variables adjusting for age, and Chi-square test of independence for categorical variables. In a preliminary set of analyses, we used linear regression models to identify important predictors and gain insight into the relationship between the predictors and $\Sigma$ PCBs. $\Sigma$ PCBs were modeled as the logarithm to base $10\left(\log _{10}\right)$ of the sum of 35 PCB congeners (ng/g wet weight). We adjusted for total lipids as a covariate because it may be less prone to bias in epidemiologic models than using lipidstandardized PCB values (Schisterman et al. 2005). Analyses with lipid-standardized PCB concentrations were also conducted for comparison. Prior to conducting the regression analysis, covariates were selected that have been shown in the literature to be significantly associated with serum PCB levels (e.g. Garabrant et al., 2009, Laden et al., 1999, Sweeney at al., 2001). The base factors selected were $\log _{10}$ transformed total lipids, age (centered at the mean of 55), age squared (centered at the mean of 55 and squared), sex, race, BMI (centered at the mean of 31.2), and current smoking. Additional study variables were evaluated using "base+1" multiple 
regression models, including interaction terms. Effect estimates are displayed in terms of multiplicative factors for PCBs (i.e., $10^{\beta}$ where $\beta$ is the slope from the regression model for $\log _{10}$ PCBs).

Study variables that were statistically significant $(\mathrm{p}<0.10)$ based on the base +1 regression analysis were included in a stepwise regression analysis to identify a subset of variables that are independent predictors of residents' body burden of PCBs. In this phase of analysis, logtransformed total lipids were forced into the model. Stepwise selection adds one variable at a time to the model based on the largest $F$ statistic and an entry significance level of $\mathrm{p}=0.25$. At each additional step, the stepwise process evaluates all variables added to the model and removes any variable that does not have an $F$ statistic significant at the $\mathrm{p}=0.05$ level. A final multivariate regression model including parameters was then evaluated. We examined the influence of total months of breastfeeding and total months pregnant using the stepwise variable selection process to determine the best predictor model for women only. Stepwise regression was also used to assess if the predictor factors are differentially associated with selected individual PCB congeners (PCBs 28, 66, 74, 99, 118, 156, 170, 187, 194, 206, 209). These congeners represent most historically and currently considered toxicity groupings defined by structure and activity, such as those recently reviewed by Warner et al. (2012), taking into account detection and correlation in human sera. Sensitivity analyses were conducted by excluding influential observations for important predictors, as well as by excluding the highest $1 \%$ or $5 \%$ of serum PCB results.

Among the base factors in the initial base+1 regression models, missing values were observed for current smoking status and BMI. The nine missing values for current smoking status ( 1 for 
yes, 0 for no) were imputed using Proc MI (SAS/STAT® 9.1); and the two missing values for BMI were set equal to the mean of 31.2. For the stepwise phase of analysis, values $(0,1)$ were imputed for educational status, alcohol consumption, dietary variables and PCB occupational exposure. The imputation for the stepwise phase of the analysis included only the variables with missing values and took into account patterns of missing data. The frequency of missing data for a variable ranged from $0.8 \%$ to $14.2 \%$. We used Proc MI with 5 imputations to impute missing values for these binary explanatory variables. The Markov Chain Monte Carlo (MCMC) algorithm produced imputed values that were set to 0 or 1 based on the distribution of nonmissing values. Analysis was performed to assess whether missing information was associated with a variable of interest. A large proportion of participants had missing information (or refused to provide it) on income (28\%); this information was not missing randomly, with a much higher proportion of missing data for African-Americans. We did not use the income variable after the initial analysis because of concerns that its missing mechanism might not be appropriate for multiple imputation (Little and Rubin, 2002). Missing data was not found to be associated with any variables of interest besides income. Analysis with imputations returned similar results as models restricted to participants with complete information.

\section{Results}

Selected demographic characteristics are presented in Table 1. Participants were 54\% white, $46 \%$ African-American, and mostly female (70\%). African-American participants were on average 2 years younger than White participants (means of 54 vs. 56 years). Participants lived at their current addresses for an average of 19 years and the average length of residence in Anniston was almost 30 years. Obesity was common; about $54 \%$ of the study population had a BMI greater 
than $30 \mathrm{~kg} / \mathrm{m}^{2}$, with a greater percentage for African-Americans at 60\%. Most participants $-89 \%$ of African-Americans and 79\% of Whites - lived in west Anniston, the part of the city closer to the former PCB production facility (Figure 1). Smoking prevalence was similar across race groups. A greater proportion of African-Americans reported alcohol consumption in the past 30 days. Dietary and occupational characteristics of the study population by race are shown in Table 2. Notably, larger proportions of African-Americans reported consumption of local fish and livestock, and almost $45 \%$ more reported having eaten local clay (66.9\% vs. $22.7 \%)$. Selfreported responses to potential occupational exposure to PCBs or other chemicals were similar, except a greater proportion of African-Americans than Whites (37.6\% versus 28.75) reported possible occupational exposure to chemicals or heavy metals. 
Table 1. Selected characteristics of Anniston Community Health Survey participants ( $n=765)$.

\begin{tabular}{|c|c|c|c|}
\hline $\begin{array}{l}\text { Characteristic (number of missing } \\
\text { responses) }{ }^{\mathrm{a}}\end{array}$ & $\begin{array}{l}\text { African-Americans } \\
\qquad(\mathrm{n}=\mathbf{3 5 3})\end{array}$ & $\begin{array}{l}\text { Whites } \\
(n=412)\end{array}$ & $\begin{array}{c}\text { Total } \\
(\mathbf{n}=765)\end{array}$ \\
\hline & & netric Mean $(95 \%$ & \\
\hline \multirow[t]{2}{*}{ Total PCBs - ng/g wet weight } & $5.03(4.41-5.73)$ & $2.05(1.83-2.28)^{\mathrm{b}}$ & $3.09(2.96-3.25)$ \\
\hline & \multicolumn{3}{|c|}{ Mean \pm Std. Error } \\
\hline Age in years & $53.6 \pm 0.8$ & $55.9 \pm 0.8^{\mathrm{c}}$ & $54.9 \pm 0.6$ \\
\hline BMI $-\mathrm{kg} / \mathrm{m}^{2}(2)$ & $31.9 \pm 0.4$ & $30.7 \pm 0.4^{\mathrm{d}}$ & $31.2 \pm 0.3$ \\
\hline Total years of residence & $26.4 \pm 1.0$ & $31.1 \pm 1.0^{\mathrm{d}}$ & $28.9 \pm 0.7$ \\
\hline Years at current residence & $17.7 \pm 0.9$ & $19.8 \pm 0.8$ & $18.8 \pm 0.6$ \\
\hline Distance from the plant - km (25) & $2.4 \pm 0.06$ & $4.2 \pm 0.1^{\mathrm{d}}$ & $3.4 \pm 0.07$ \\
\hline No. of pregnancies & $3.3 \pm 0.1$ & $3.0 \pm 0.1$ & $3.2 \pm 0.1$ \\
\hline \multirow[t]{2}{*}{ No. of drinks in the past 30 days $(21)^{\mathrm{a}}$} & $11.6 \pm 1.6$ & $8.7 \pm 2.2$ & $10.0 \pm 1.4$ \\
\hline & \multicolumn{3}{|c|}{ Percentage (non-missing) } \\
\hline Female & $70.3 \%$ & $70.2 \%$ & $70.2 \%$ \\
\hline \multicolumn{4}{|l|}{ Age groups - years } \\
\hline $18-39$ & $17.9 \%$ & $19.4 \%^{\mathrm{e}}$ & $18.7 \%$ \\
\hline $40-59$ & $45.6 \%$ & $34.7 \%$ & $39.7 \%$ \\
\hline $60+$ & $36.5 \%$ & $45.9 \%$ & $41.6 \%$ \\
\hline \multicolumn{4}{|l|}{ BMI classification } \\
\hline Normal $<25$ & $17.4 \%$ & $22.6 \%{ }^{\mathrm{e}}$ & $20.2 \%$ \\
\hline Overweight 25-29 & $22.5 \%$ & $29.4 \%$ & $26.2 \%$ \\
\hline Obese $\geq 30$ & $60.1 \%$ & $48.1 \%$ & $53.6 \%$ \\
\hline Reside in west Anniston & $89.2 \%$ & $79.4 \%{ }^{\mathrm{e}}$ & $83.9 \%$ \\
\hline Current smoker $(9)^{\mathrm{a}}$ & $31.3 \%$ & $31.8 \%$ & $31.6 \%$ \\
\hline Drank alcohol in the past 30 days $(13)^{\mathrm{a}}$ & $37.1 \%$ & $21.4 \%^{\mathrm{e}}$ & $28.6 \%$ \\
\hline Currently married & $33.1 \%$ & $55.1 \%^{\mathrm{e}}$ & $45.0 \%$ \\
\hline High school graduate $(6)^{\mathrm{a}}$ & $71.3 \%$ & $66.6 \%$ & $68.8 \%$ \\
\hline
\end{tabular}

a A response of "don't know" or refusal is counted as missing.

${ }^{\mathrm{b}} \mathrm{p}<0.0001$ for African-Americans compared with Whites using t-test for $\log _{10}$ sum of the 35 PCBs.

${ }^{\mathrm{c}} \mathrm{p}<0.05$ for African Americans compared with Whites using t-test.

${ }^{d} \mathrm{p}<0.05$ for African Americans compared with Whites using analysis of covariance adjusting for age.

${ }^{\mathrm{e}} \mathrm{p}<0.05$ for African-Americans compared with Whites using Chi-square test of independence. 
Figure 1. Participant residence density in Anniston, Alabama, with former PCB facility site and waterways demarcated.

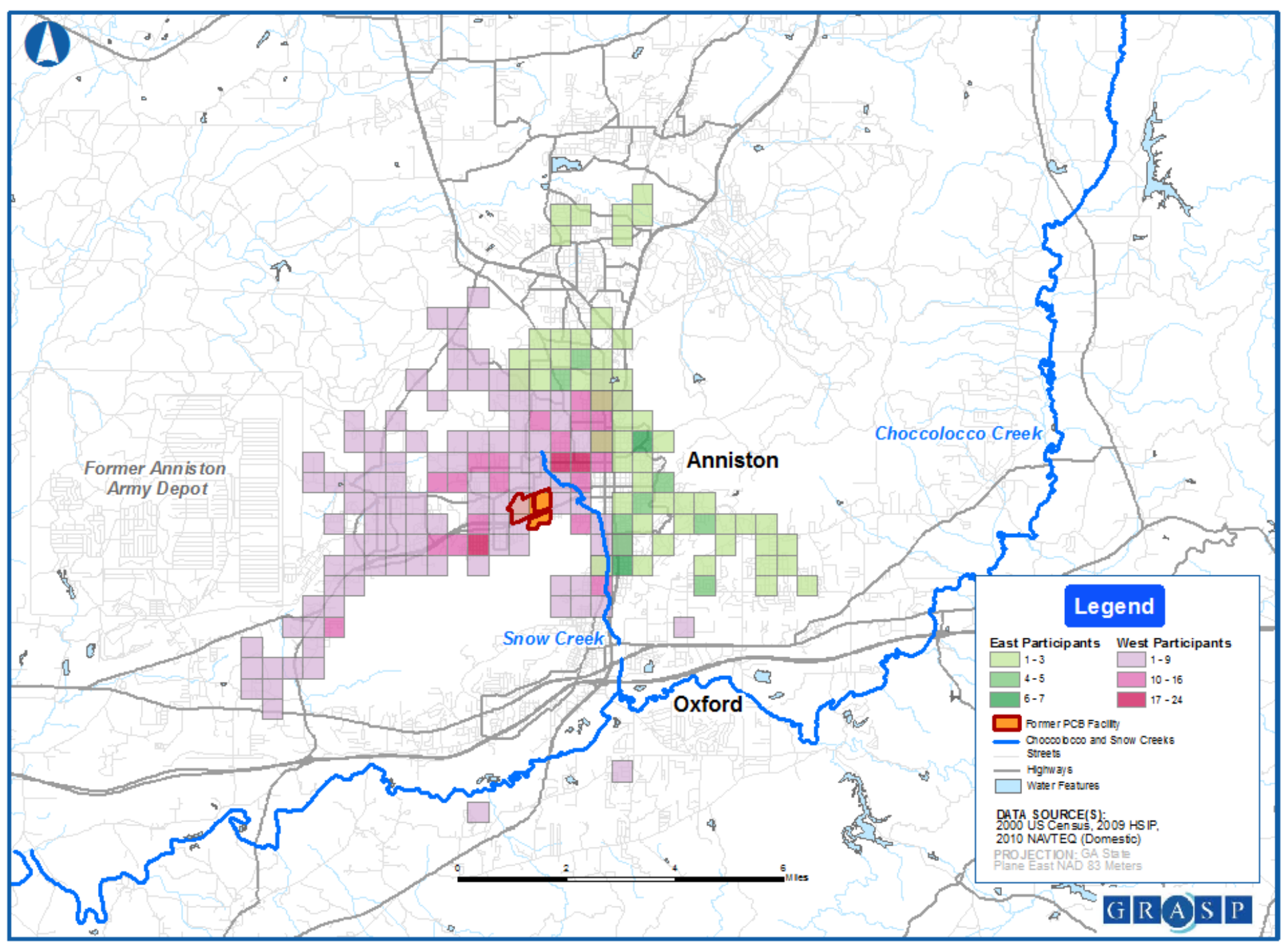

Ge ospatial Re search, Analysis \& Services Program 
Table 2. Consumption of locally produced foods and occupational exposure in Anniston Community Health Survey participants.

\begin{tabular}{lccc}
\hline $\begin{array}{l}\text { Characteristic (number of missing } \\
\text { responses) }\end{array}$ & $\begin{array}{c}\text { African-Americans } \\
(\mathrm{n}=353)\end{array}$ & $\begin{array}{c}\text { Whites } \\
(\mathrm{n}=412)\end{array}$ & $\begin{array}{c}\text { Total } \\
(\mathrm{n}=765)\end{array}$
\end{tabular}

\section{Percentage (non-missing)}

\section{Ever eaten:}

locally raised hogs, chicken or

$77.8 \%$

$55.6 \%^{\mathrm{b}}$

$66.1 \%$

other livestock (51)

fish from Snow Creek,

$74.8 \%$

$50.5 \%^{\mathrm{b}}$

$61.7 \%$

Choccolocco Creek, or Lake Logan

Martin (63)

local clay (34)

$66.9 \%$

$22.7 \%^{\mathrm{b}}$

$43.6 \%$

locally grown vegetables (9)

$93.1 \%$

$90.2 \%$

$91.5 \%$

Ever exposed at a job to:

PCBs (109)

$27.0 \%$

$27.3 \%$

$27.1 \%$

Transformers fluids (45)

$22.8 \%$

$24.3 \%$

$23.6 \%$

Ionizing radiation (70)

$14.2 \%$

$11.6 \%$

$12.8 \%$

Lead, boron, mercury or cadmium

$37.6 \%$

$28.7 \%^{\mathrm{b}}$

$32.7 \%$

(81)

Fertilizers (37)

$21.6 \%$

$26.4 \%$

$24.2 \%$

Pesticides (40)

$25.3 \%$

$28.2 \%$

$26.9 \%$

Herbicides (52)

$18.8 \%$

$22.6 \%$

$20.9 \%$

Solvents (50)

$33.6 \%$

$37.9 \%$

$35.9 \%$

a A response of don't know or refusal is counted as missing.

${ }^{\mathrm{b}} \mathrm{p}<0.05$ Whites compared with African-Americans using Chi-square test of independence. 
Of the 35 measured PCB congeners, the proportion of results above the individual LOD was greater than $60 \%$ for 26 congeners in White participants and for 27 congeners among AfricanAmericans. Median LODs ranged from $0.4 \mathrm{ng} / \mathrm{g}$ lipid to $1.3 \mathrm{ng} / \mathrm{g}$ lipid. The geometric mean $\Sigma$ PCBs (ng/g wet weight) was significantly higher for African-American compared to White participants: 5.03 (95\% C.I. 4.41-5.73) and 2.05 (95\% C.I. 1.83-2.28) respectively (Table 1). Lipid-adjusted (ng/g) geometric mean $\Sigma$ PCBs for African-American and White participants were 865 (95\% C.I. 762-983) and 331 (95\% C.I. 297-369) respectively.

Age is the most important predictor of PCB levels, and a scatter plot of log-transformed PCB levels and age by race with linear regression lines for age are shown in Figure 2. Serum PCB concentrations are higher among older participants. African-American participants consistently had higher PCB concentrations than Whites had, with a greater difference noted among older age cohorts. 
Figure 2. Scatter plots of serum PCBs and age by race (logarithm to base 10 sum of PCBs) and linear regression lines.

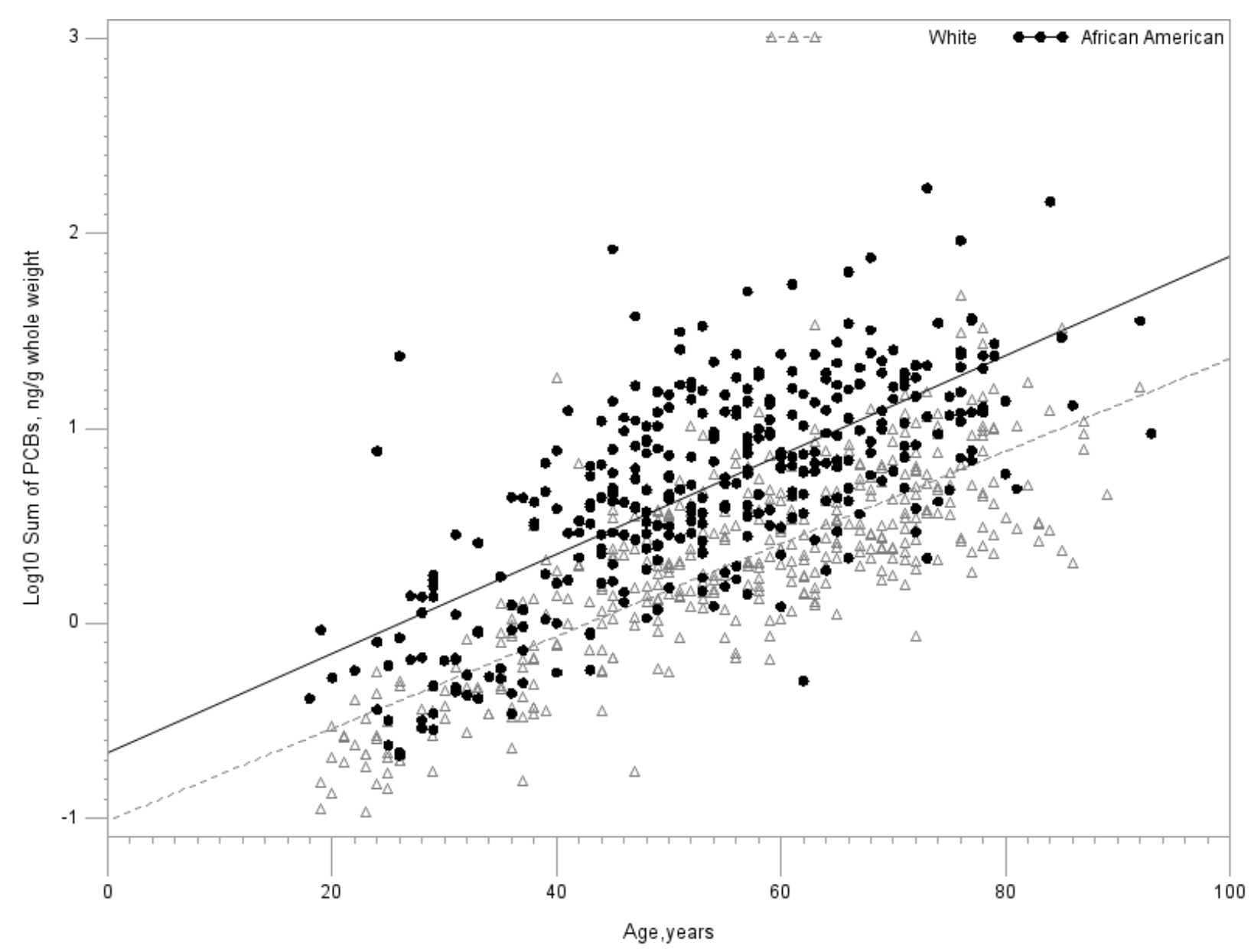

$\log _{10}$ (sum of PCBs, whole weight $)_{\text {White }}=-1.01282+0.02369($ age $)$.

$\log _{10}(\text { sum of PCBs, whole weight })_{\text {African-American }}=-0.66473+0.02547$ (age) . 
The base +1 linear regression results, showing relationships between the $\Sigma$ PCBs and individual variables in addition to base factors, are shown in Table 3. While most base factors were statistically significant, sex and BMI were not significantly related to $\Sigma$ PCBs. The variables in Table 3 that were statistically significant at $\mathrm{p}<0.10$ were included in the stepwise regression analysis. These variables were age (centered), age $^{2}$ (centered), race, sex, current smoking status, education, alcohol consumption in the past 30 days, total years of residence in Anniston, residence in West Anniston, ever eaten locally raised livestock, ever eaten local fish, ever eaten local vegetables, ever eaten local clay, home gardening, and occupational exposure to PCBs. 
Table 3. Base +1 linear regression results for $\Sigma \mathrm{PCB}$ in Anniston Community Health Survey participants.

\begin{tabular}{|c|c|c|c|c|}
\hline Parameter & $\begin{array}{l}\text { Number } \\
\text { Missing* }\end{array}$ & $10^{\beta}$ & P-value & Partia \\
\hline \multicolumn{5}{|l|}{ Base Model } \\
\hline $\log _{10}$ (total lipids) & & 5.1150 & $<0.0001$ & 0.0229 \\
\hline Age at interview- 55 years ${ }^{a}$ & & 1.0548 & $<0.0001$ & 0.4396 \\
\hline Age at interview- 55 years ${ }^{2 \mathrm{a}}$ & & 0.9995 & $<0.0001$ & 0.0317 \\
\hline Race ( 1 for African-American, 0 for Whites & & 2.8301 & $<0.0001$ & 0.1578 \\
\hline Sex ( 1 for female, 0 for male) & & 1.0109 & 0.8563 & 0.0000 \\
\hline BMI $-31.2\left(\mathrm{~kg} / \mathrm{m}^{2}\right)^{*}$ & 2 & 0.9972 & 0.4465 & 0.0008 \\
\hline Current Smoker ( 1 for yes, 0 for no) & 9 & 1.1741 & 0.0102 & 0.0030 \\
\hline
\end{tabular}

\section{Other Variables}

Education (1 for high school graduate or more, 0 for less than high school graduate)

0.0029

0.0040

Annual Income ( 1 for $\geq \$ 20 \mathrm{~K}, 0$ for $<\$ 20 \mathrm{~K}$ )

Drank alcohol in past 30 days ( 1 for yes, 0 for no)

Residence in West Anniston (1 for West, 0 for East)

Total years of residence (in Anniston)

Years at current residence

1.0029

0.1395

0.0010

Distance from the plant to current residence

$(\mathrm{km})$

0.9762

0.1176

0.0012

Have you ever eaten ( 1 for yes, 0 for no):

Locally raised livestock

Local fish

1.4560

0.0001

0.0193

Local clay

1.3199

0.0001

0.0087

Locally grown vegetables

(home-grown)

1.4230

0.0004

0.0057

Have you ever worked in your own home garden? ( 1 for yes, 0 for no)

1.2064

0.0037

0.0039

Have you ever worked at a job where you might have been exposed to? ( 1 for yes, 0 for no)

Fertilizers 
Herbicides

Solvents

Electrical transformers

Ionizing radiation

PCBs

Chemicals such as lead, boron, mercury or cadmium

Interactions:

Age $x$ Sex

Age $x$ Race

Race $x$ Sex

Race $x$ Ever eaten locally raised livestock

Race $x$ Ever eaten local fish

Race $x$ Ever eaten local clay

Females only:

Number of pregnancies

Total months breastfeeding
52

50

45

70

109

81
1.0717

1.070

1.0887

1.0067

1.199

1.0499

1.0102

1.0035

1.1790

1.2613

0.9275

1.2199

0.9937

0.9959 ${ }^{\text {a }}$ Age at interview was centered at 55 years, and BMI was centered at $31.2 \mathrm{~kg} / \mathrm{m}^{2}$.
$0.3356 \quad 0.0004$

$0.2261 \quad 0.0006$

$0.2234 \quad 0.0007$

$0.9371 \quad 0.0000$

$0.0039 \quad 0.0044$

$0.4616 \quad 0.0003$

0.0029

0.0005

0.0009

0.0017

0.0002

$0.1055 \quad 0.0012$

$0.6736 \quad 0.0001$

$0.1089 \quad 0.0018$ 
The best predictor model of PCB levels for the study population is shown in Table 4. Total lipids was forced into the model as a covariate and the other covariates remained significant $(\mathrm{P}<0.05)$ via a stepwise regression analysis. The most important independent predictors are age and race, with age ${ }^{2}$ also significantly associated with PCB levels. The quadratic component for age indicates that the strong positive relationship between PCB levels and age diminishes among older participants. Having ever eaten potentially contaminated locally caught fish was also a highly significant predictor. Current smoking was positively associated with PCB levels, while higher educational attainment was negatively associated with PCB levels. Residing in west Anniston and total years of residence in Anniston were positively associated with $\Sigma$ PCBs. A small age by sex interaction was noted, indicating that the increase in PCB levels with age was steeper for women than for men. Whereas below age 50, men tended to have higher PCB levels than women, the opposite was true among older participants. Significant interactions were found that indicated that the associations between PCB levels and having ever eaten locally raised livestock and local clay were much stronger among African-Americans than among White participants. After accounting for the effect of consuming local fish, the effects of eating local livestock or local clay were not statistically significant overall. There was a high degree of concordance among responses to ever eaten local fish, livestock and clay. Excluding influential observations for important predictors or excluding the highest $1 \%$ or $5 \%$ of the PCB results did not materially change any of our results. 
Table 4. Significant predictors of $\Sigma$ PCBs in Anniston Community Health Survey participants.

\begin{tabular}{|c|c|c|c|}
\hline Parameter & $10^{\beta}$ & P-value & Partial R \\
\hline Intercept & 0.0129 & $<0.0001$ & \\
\hline $\log _{10}($ total lipids $)$ & 5.4135 & $<0.0001$ & .0229 \\
\hline Age at interview- 55 years ${ }^{\text {a }}$ & 1.0510 & $<0.0001$ & .4396 \\
\hline Age at interview-55 years ${ }^{2}$ a & 0.9995 & $<0.0001$ & .0317 \\
\hline Race ( 1 for African-American, 0 for White) & 2.6683 & $<0.0001$ & 0.1578 \\
\hline Current smoker ( 1 for yes, 0 for no) & 1.1892 & 0.0036 & 0.0036 \\
\hline $\begin{array}{l}\text { Education ( } 1 \text { for high school graduate or more, } \\
0 \text { for less than high school graduate) }\end{array}$ & 0.8747 & 0.0237 & 0.0041 \\
\hline Residence in West Anniston ( 1 for West, 0 for East) & 1.2124 & 0.0084 & 0.0047 \\
\hline Total years of residence (in Anniston) & 1.0058 & 0.0003 & 0.0071 \\
\hline $\begin{array}{l}\text { Ever eaten local fish } \\
\text { (1 for yes, } 0 \text { for no) }\end{array}$ & 1.3487 & 0.0001 & 0.0117 \\
\hline \multicolumn{4}{|l|}{ Model R-Square $=0.6832$} \\
\hline \multicolumn{4}{|l|}{ Adjusted model R-Square $=0.6794$} \\
\hline \multicolumn{4}{|l|}{ Add to predictor model: } \\
\hline Ever eaten locally raised livestock & 1.0916 & 0.2551 & 0.0031 \\
\hline Race by (eaten local livestock) & 1.2902 & 0.0307 & 0.0019 \\
\hline \multicolumn{4}{|l|}{ Model R-Square $=0.6882$} \\
\hline \multicolumn{4}{|l|}{ Adjusted model R-Square $=0.6837$} \\
\hline \multicolumn{4}{|l|}{ Add to predictor model: } \\
\hline Ever eaten local clay & 1.003 & 0.9709 & 0.0024 \\
\hline Race by (eaten local clay) & 1.3214 & 0.0175 & 0.0019 \\
\hline \multicolumn{4}{|l|}{ Model R-Square $=0.6879$} \\
\hline \multicolumn{4}{|l|}{ Adjusted model R-Square $=0.6833$} \\
\hline \multicolumn{4}{|l|}{ Add to predictor model: } \\
\hline Sex & 1.0135 & 0.8149 & 0.0000 \\
\hline Age by sex interaction & 1.0077 & 0.0458 & 0.0017 \\
\hline \multicolumn{4}{|l|}{ Model R-Square $=0.6849$} \\
\hline Adjusted model R-Square $=0.6803$ & & & \\
\hline
\end{tabular}


Regression results for selected individual PCBs (Table 5) echoed findings from analyses of ¿PCBs in general, although specific patterns emerged for associations seen for some congeners with female sex and with BMI. These associations were positive for less-chlorinated congeners (PCBs 28, 66, 74, 99, 118) but were negative for more highly chlorinated congeners (PCBs 170, 194, 206, and 209 for BMI; only PCB 194 for female sex). A negative association was seen with current smoking for PCBs 28 and 66; however, the relatively low $\mathrm{R}^{2}$ for these PCBs indicate the influence of factors not accounted for by the parameters in this study.

\section{Discussion}

Significant associations between serum PCB concentrations and age, race, residential variables, current smoking, and local fish consumption, as well as an inverse association with education level, were observed in the Anniston Community Health Study. Several interaction terms also were observed to be significant, including a small age by sex interaction and, among AfricanAmerican participants, positive associations with serum PCB levels for having ever eaten locally raised livestock and for having ever eaten local clay. Age and race were the most important predictors of serum PCB levels, together explaining $60 \%$ of the total variability in PCB serum levels. Total serum lipids and having ever consumed local fish explained $2.3 \%$ and $1.2 \%$ of the variability, respectively, while current smoking, educational attainment, the residential variables,

and each significant interaction term each accounted for less than $1 \%$ of the variability (Table 4). Sample selection focused on the area in close vicinity of the former PCB production facility. 
Table 5. Significant predictors of selected individual PCB serum concentrations in Anniston Community Health Survey participants. ${ }^{1}$

\begin{tabular}{|c|c|c|c|c|c|c|c|c|c|c|c|c|}
\hline & \multicolumn{12}{|c|}{ PCB } \\
\hline & 28 & 66 & 74 & 99 & 118 & 153 & 156 & 170 & 187 & 194 & 206 & 209 \\
\hline Variable & $10^{\beta}$ & $10^{\beta}$ & $10^{\beta}$ & $10^{\beta}$ & $10^{\beta}$ & $10^{\beta}$ & $10^{\beta}$ & $10^{\beta}$ & $10^{\beta}$ & $10^{\beta}$ & $10^{\beta}$ & $10^{\beta}$ \\
\hline Intercept & 0.2264 & 0.1383 & 0.3455 & 0.2111 & 0.8204 & 2.9517 & 0.2725 & 0.4902 & 0.3954 & 0.0638 & 0.0467 & 0.0264 \\
\hline $\log 10$ (total lipids) & 4.2913 & 3.6460 & 5.2914 & 5.2081 & 3.821 & 4.6692 & 5.6272 & 6.1608 & 6.0989 & 11.947 & 10.9257 & 11.0375 \\
\hline Age at interview -55 years & 1.0229 & 1.0337 & 1.0494 & 1.0425 & 1.0533 & 1.0497 & 1.0516 & 1.0494 & 1.0520 & 1.0561 & 1.0656 & 1.0796 \\
\hline Age at interview - 55 years ${ }^{2}$ & & & 0.9997 & & & & & 0.9993 & & 0.9992 & & \\
\hline Race (1 for African American, 0 for White) & & 2.0907 & 1.7864 & 3.7910 & 3.3441 & 2.8841 & 2.0481 & 2.2776 & 3.1947 & 2.0491 & 1.7873 & 1.7170 \\
\hline Gender (1 for Female, 0 for Male) & 1.2512 & 1.4192 & 1.6255 & 1.2075 & 1.6746 & & & & & 0.8035 & & \\
\hline BMI - 31 & 1.0170 & 1.0287 & 1.0131 & 1.0203 & 1.0320 & & 0.9899 & 0.9851 & & 0.9744 & 0.9798 & 0.9754 \\
\hline Current smoker ( 1 for yes, 0 for no) & 0.7124 & 0.777 & & 1.3115 & & & 1.1565 & 1.1908 & 1.2725 & & & \\
\hline $\begin{array}{l}\text { Education (1 for high school graduate or more, } \\
\text { O for less than high school graduate) }\end{array}$ & & & & & & & & 0.8721 & & 0.8112 & 0.8250 & 0.7832 \\
\hline $\begin{array}{l}\text { Drank alcohol in past } 30 \text { days ( } 1 \text { for yes, } 0 \text { for } \\
\text { no) }\end{array}$ & 1.1702 & 1.354 & & & & & & & & 1.1863 & 1.2262 & 1.1815 \\
\hline Resides in West Anniston ( 1 for yes, 0 for no) & & & & 1.2567 & 1.249 & 1.1995 & 1.2301 & 1.1684 & 1.2295 & 1.0058 & 1.3408 & 1.3767 \\
\hline Total years of residence in Anniston & & & & 1.0048 & 1.0045 & 1.0053 & 1.0040 & 1.0047 & 1.0057 & & 1.0097 & 1.0143 \\
\hline Years at current address & & & & & & & & & & & & \\
\hline Distance from plant to residence $(\mathrm{km})$ & 0.9387 & 0.9559 & & & & & & & & & 0.9580 & 0.9379 \\
\hline
\end{tabular}




\begin{tabular}{|c|c|c|c|c|c|c|c|c|c|c|c|c|}
\hline eat locally raised livestock ( 1 for yes, 0 for no) & & & & & & 1.1872 & 1.2528 & 1.2026 & 1.1963 & 1.4362 & 1.2282 & 1.2394 \\
\hline eat local fish ( 1 for yes, 0 for no) & & 1.2022 & 1.2318 & 1.4057 & 1.4609 & 1.3264 & 1.1824 & 1.2519 & 1.4077 & & 1.1735 & \\
\hline eat clay ( 1 for yes, 0 for no) & & & & & & & & & & 1.2083 & 1.2547 & 1.2780 \\
\hline eat local vegetables ( 1 for yes, 0 for no) & & & & & & & & & & & & 1.3513 \\
\hline exposed at work to PCBs ( 1 for yes, 0 for no) & 0.8664 & & & & & & & & & 1.1858 & & \\
\hline R-Square & 0.29 & 0.39 & 0.63 & 0.53 & 0.59 & 0.63 & 0.69 & 0.70 & 0.65 & 0.70 & 0.71 & 0.74 \\
\hline
\end{tabular}

${ }^{1}$ The $10^{\beta}$ estimates for covariates are shown only when $p<0.05$. 
Interaction terms included in the final model revealed several patterns related to PCBs in subgroups. Statistically significant interaction terms for race by having ever eaten local livestock or clay indicated that consumption of these was associated with serum PCB concentrations among African-American participants, but not significantly so among White participants. A large majority of African-American participants lived in close proximity of former PCB plant in the west Anniston neighborhood (89\%). More African-Americans reported having ever consumed local livestock, fish, and clay, but the dietary variables were not detailed enough to distinguish the time period or frequency of consumption. It is possible that, in addition to being more likely to ever have consumed local livestock and clay, African-American participants also ate local meat and clay more often or at periods more pertinent to higher PCB contamination during the 1950s and 1960s. Total PCB concentrations were two to three times higher in Anniston AfricanAmericans than in Whites (Pavuk et al., 2009, 2014), exceeding the reported differences by race attributed to consumption of PCB-contaminated catfish by non-Hispanic blacks in the U.S. (Weintraub and Birnbaum, 2008). We cannot exclude the possibility that the observed interactions may be due partly to varying sample size and the accompanying power to detect an association. We also note that the apparent associations with race are likely indicative of the influence of residential and behavioral factors that resulted in higher exposure to PCBs for African-Americans than for Whites, and there may be other important predictors that we did not capture.

We observed an age by sex interaction that showed a slightly steeper increase in PCB levels with age for women than for men. Below age 50, men tended to have higher serum concentrations of PCB than did women, but the opposite was true among older participants. The geometric means 
for the sum of PCBs in the youngest age group were about one-tenth of those in the oldest group (60 years or older), at 103.8 vs. 1029 ng/g lipid (not shown). After adjustment for age, BMI, race, and current smoking, the geometric mean for the sum of PCBs was marginally higher in men than in women (526 ng/g lipid vs. $516 \mathrm{ng} / \mathrm{g}$ lipid), but the difference was not statistically significant (Pavuk et al., 2014). A contributing factor for this interaction may have been menopause, which has been found to be associated with a variety of metabolic changes and increased prevalence of metabolic syndrome (Carr, 2003; Lovejoy et al., 2008; Abildgaard et al., 2013). It is also possible that the observed age by sex interaction is due to variation in local fish, livestock, or clay consumption by sex and/or age. Higher percentages of men reported ever eating each of these, but the differences in proportions were not statistically significant (p-values ranged from 0.39 to 0.72 ). The mean ages of participants who reported ever eating local fish, livestock, or clay were similar to those of participants who had not. However, the lack of data on quantity or timing of consumption limits the conclusions that may be drawn regarding these dietary variables. Notably, we observed the age by sex interaction counter to the expectation that men over 50 would have been more likely than women of the same age to have been occupationally exposed to PCBs at Anniston's production facility.

We observed higher serum PCB levels among participants who reported ever eating local fish than among those who did not. Based on the collected data, we could not distinguish past from current fish consumption. Fish advisories adopted by ADPH in the 1990s for streams and lakes around Anniston are still in place today, but only about half of our study participants reported awareness of these advisories at the time of the survey (Bartell et al., 2011). In catfish and bass fillets collected around Anniston, mean total PCBs of 3 to 5 ppm in fish from Snow Creek and 
around 1 ppm for Lake Logan Martin fish were found (Lorentz, 2005). The U.S. Food and Drug Administration has set a tolerance limit of $2 \mathrm{ppm}$ of PCBs as "unavoidable poisonous or deleterious substances" in fish to be consumed by humans (FDA, 2012).

Overall, having ever consumed local fish was a stronger predictor than the interaction terms for race by ever eating local livestock or clay. No measurements of PCBs in livestock, clay, or wildlife were available, although one court document detailed that local hogs - purchased in 1970 by Monsanto from Anniston residents - had PCB levels in fat as high as 19,000 ppm (Chemical Industry Archives, 2001).

The consumption of raw or baked clay has been documented around the world (Young et al., 2011), including in rural areas of the southeastern United States (Grigsby et al., 1999; Vermeer and Frate, 1979). A 1976 study of PCB adsorption on soils showed that illite clay was highly adsorptive for the three congeners tested, with higher adsorption for highly chlorinated congeners (Haque and Schmedding, 1976). PCBs and PCDD/Fs have been detected in types of clay that are often eaten (Horii et al., 2011; Reeuwijk et al., 2013), but we had no information on PCB concentrations in local clay.

Participants had an average length of residence in Anniston of almost 30 years and an average of 19 years at the current residence. As mentioned, residing in west Anniston and total years of residence in Anniston were positively associated with PCB body burdens. These associations 
were significant when age was included in the model, suggesting that serum PCB levels among participants may have been influenced by exposure through local food (as discussed above), occupations in PCB manufacturing, soil, air, or other factors specific to life in Anniston. An earlier study of PCB exposure in Anniston did not provide evidence of associations with PCB levels in residential soil or dust (Orloff et al., 2003).

Detailed occupational history was not available in the survey data to compare PCB levels between participants who did not report occupational exposure and those with employment histories related directly to PCB production or those who worked in the production facilities after the PCB production ended.

For the most part, regression results for individual PCBs (Table 5) mirrored findings from analyses of $\Sigma$ PCBs. Differences included variation in associations observed with female sex and with BMI; less-chlorinated PCBs were positively associated with these variables, but highly chlorinated PCBs were negatively associated. Although several studies show negative associations for $\mathrm{PPCBs}$ with BMI and/or female sex (Agudo et al., 2009; Bräuner et al., 2011; Humblet et al., 2010), the relationships between PCB concentrations and sex and BMI appear to be complex (Garabrant et al., 2009). Our congener-specific findings were in agreement with Agudo et al. (2009), who found in a study of Spanish adults that the less-chlorinated PCBs 118 and 138 were positively associated with BMI, while the higher-chlorinated PCBs 153 and 180 were negatively associated. Likewise, Roos et al. (2013) found that serum concentrations of PCBs 105 and 118 were positively associated with measures of adipose tissue in an elderly Swedish population, whereas more highly chlorinated PCBs $(153,156,157,169,170,180,194$, 
206, and 209) were negatively associated; Lee et al. (2012) reported similar findings with regard to chlorination of congeners in analyses of relationships between waist circumference and PCBs.

Another departure from the $\mathrm{\Sigma} \mathrm{PCBs}$ results seen in the congener-specific analyses was a "protective" effect of current smoking for PCBs 28 and 66. Negative associations between smoking and PCBs have been documented (Brown and Lawton, 2001; Garabrant et al., 2009); smoking may reduce PCB concentrations through aryl hydrocarbon receptor activation and induction of cytochrome P450 and other enzymes, enabling elimination of dioxin-like compounds (Deutch and Hansen 1999; Zevin and Benowitz 1999).

We compared our results to several large studies of environmental exposure to PCBs that have been able to examine in detail the predictors of PCBs at concentrations similar to those found in Anniston. In 240 controls from the Nurses' Health Study, age, cholesterol, parity, and U.S. region were important predictors of PCBs in serum collected in 1989-1990 (Laden et al., 1999). Mean total PCBs (sum of 16 ortho-substituted PCBs) ranged between $4.43 \mathrm{ppb}$ and $5.57 \mathrm{ppb}$ wet weight, similar to the geometric mean serum levels (total of 35 PCBs) of 5.03 ppb for AfricanAmericans but higher than 2.05 ppb for Whites in Anniston in 2005-2007 (Pavuk et al., 2014). As in our study, BMI was not an important predictor; neither was the length of lactation. With the exception of fish and eggs, no other dietary variables were significant determinants of PCB levels with age, cholesterol and region in the model. Dietary practices were evaluated in a detailed questionnaire (but analyzed as 'ever' consumed in the regression models). Another study examined Michigan women from a cohort exposed to PBBs and PCBs in 1970s (Sweeney et al., 2001). Age, BMI, having ever been pregnant, and Great Lakes fish consumption were 
associated with higher serum PCB concentrations. Milk, beef, and alcohol consumption were not important predictors, nor was cigarette smoking. Mean total PCB levels ranged from $3.4 \mathrm{ppb}$ to $8.1 \mathrm{ppb}$ wet weight among different categories of age at enrollment. Most women had PCB levels that remained stable or decreased between 1974 and 1995, although levels increased for $12 \%$ of women during that time period. Changes in PCB levels over time in Anniston will be examined in a follow-up study.

Determinants of PCB levels in populations living near contaminated areas have been studied elsewhere, such as at the Superfund site at New Bedford, Massachusetts. There, gardening and consumption of local dairy and organ meat predicted changes in cord serum levels in different groups of PCBs in newborns of mothers living near the Superfund site. Consumption of local fish, neighborhood social characteristics, occupation, and the residential distance from the site were not important PCB determinants in this specific group (Choi et al., 2006). In a study of 446 mothers living in a Russian town contaminated by past industrial activity, Humblet et al. (2010) found positive associations between serum total PCB concentrations and age, residential proximity to a local chemical plant, duration of local farming, and consumption of local beef, whereas negative associations were observed for longer time spent breastfeeding, recent increases in BMI, and later blood draw date. The median total PCB concentration in these women was $260 \mathrm{ng} / \mathrm{g}$ lipid, $50 \%$ lower than median concentration in the ACHS sample. The lower PCB concentrations in the Russian participants may be due to their younger age (range: 23 to 52 years). As in Anniston, a chlorinated chemicals production plant was located in the town, but the extent of PCB use at the facility is unknown. 


\section{Study strengths and limitations}

We should note that some of these associations could be observed by chance alone. As with all stepwise regression models, these results should be viewed as exploratory rather than confirmatory. However, the results presented in Table 4 represent robust and stable estimates of associations between PCB levels and their linear predictors. Adjusted coefficients of determination for the final models were high, explaining about $69 \%$ of variability in serum PCB levels. The adjusted R-squared value was 0.6859 for the model including interaction terms for race by ever having eaten locally raised livestock and race by ever having eaten local clay; addition of the age by sex interaction term raised the adjusted R-squared to 0.6871 (Table 4).

The sample was balanced by race. However, non-random selection of individuals within households resulted in underrepresentation of men and participants under age 40 in this sample, which limits generalizability of the results. Participants who provided blood specimens appeared to be demographically similar to those who only completed the questionnaire. A structured questionnaire was used to reduce recall bias on nutritional and behavioral variables, but the lack of frequency and time period information for those variables is an important limitation. Limitations also include the possibility of bias introduced by distributions of the sample by sex and age that do not reflect the study area's population; however, the selection bias due to participation in PCB litigation is negligible, considering that nearly the whole town, including children, was part of the lawsuits (21,000 of approximately 24,000 Anniston residents).

\section{Conclusion}

In summary, our results indicate that age and race are important determinants of exposure to PCBs in Anniston residents, as are the total years of residence in Anniston and residence in west 
Anniston specifically. The most likely exposure route in Anniston residents was through past consumption of contaminated local fish - and, particularly among African-American participants, local livestock and clay - associated with higher current PCB serum levels. The large-scale clean-up of surface soil on contaminated properties in Anniston, with replacement of surface soil at more than 570 properties so far (EPA, 2013), is an important measure underway to reduce the potential for future contamination of local foods. Meanwhile, further education may be necessary to increase local awareness of fish advisories in the Anniston area (ADPH, 2011) and of other ways to minimize exposure. 


\section{References}

Abildgaard, J., Pedersen, A.T., Green, C.J., Harder-Lauridsen, N.M., Solomon, T.P., Thomsen, C., Juul, A., Pedersen, M., Pedersen, J.T., Mortensen, O.H., Pilegaard, H., Pedersen, B.K., Lindegaard, B. 2013. Menopause is associated with decreased whole body fat oxidation during exercise. Am. J. Physiol. Endocrinol. Metab. 304(11), E1227-1236.

Agudo, A., Goñi, F., Etxeandia, A., Vives, A., Millán, E., López, R., Amiano, P., Ardanaz, E., Barricarte, A., Chirlaque, M.D., Dorronsoro, M., Jakszyn, P., Larrañaga, N., Martínez, C., Navarro, C., Rodríguez, L., Sánchez, M.J,, Tormo, M.J., González, C.A., 2009. Polychlorinated biphenyls in Spanish adults: determinants of serum concentrations. Environ. Res. 109(5), 620628.

ADPH (Alabama Department of Public Health), 1995. Health Consultation: Monsanto Company, Anniston, Calhoun County, Alabama. CERCLIS No. ALD004019048.

ADPH (Alabama Department of Public Health), 1996. Health Consultation: Cobbtown/Sweet Valley Community PCB Exposure Investigation. Anniston, Calhoun County, Alabama.

ADPH (Alabama Department of Public Health), 2011. Alabama Fish Consumption Advisory Guidelines 2002-2011. http://adph.org/tox/index.asp?id=1360. Accessed 01/27/2012.

ASTM (American Society for Testing and Materials), 1989. Committee on Standards Designation, D4210-89: 2-7. ASTM, Philadelphia.

ATSDR (Agency for Toxic Substances and Disease Registry), 2000a. Toxicological Profile for Polychlorinated Biphenyls (PCBs). U.S. Department of Health and Human Services, Atlanta.

ATSDR (Agency for Toxic Substances and Disease Registry), 2000b. Health Consultation: Evaluation of soil, blood \& air data from Anniston, Alabama. Monsanto Company, Anniston, Calhoun County, Alabama. CERCLIS No. ALD004019048. U.S. Department of Health and Human Services, Atlanta.

Bartell, S.M., Foushee, H.R., Devereaux, R.S., Wolff, P.E., Pavuk, M. for the Anniston Environmental Health Research Consortium, 2011. Community perceptions regarding polychlorinated biphenyl contamination, exposure, and health effects in Anniston, Alabama. Organohalogen Compds. 73, 1439-1442.

Bernert, J.T., Turner, W.E., Patterson, Jr., D.G. Needham, L.L., 2007. Calculation of serum "total lipid" concentrations for the adjustment of persistent organohalogen toxicant measurements in human samples. Chemosphere 68, 824-831.

Burns, J.S., Williams, P.L., Sergeyev, O., Korrick, S., Lee, M.M., Revich, B., Altshul, L., Patterson Jr., D.G., Turner, W.E., Needham, L.L., Saharov, I., Hauser, R. 2009. Predictors of 
serum dioxins and PCBs among peripubertal Russian boys. Environ. Health Perspect. 117(10): 1593-1599.

Bräuner, E.V., Raaschou-Nielsen, O., Gaudreau, E., LeBlanc, A., Tjønneland, A., Overvad, K., Sørensen, M., 2011. Predictors of polychlorinated biphenyl concentrations in adipose tissue in a general Danish population. Environ. Sci. Technol. 45(2), 679-685.

Carr, MC. The emergence of the metabolic syndrome with menopause. 2003. J. Clin. Endocrinol. Metab. 88(6), 2404-2411.

CDM Federal Programs Corporation, 2010. Anniston PCB Site Operable Units 1 and 2 Baseline Risk Assessment, Anniston, Alabama. Final - Part I Text, Human Health Baseline Risk Assessment Report. Contract No. 68-S7-03-04, Task Order No. 0023. U.S. Environmental Protection Agency, Washington, DC.

Chemical Industry Archives, Environmental Working Group, 2001. Trial Transcript, Owens v. Monsanto CV-96-J-440-E, (N.D. Alabama April 5, 2001), pg. 551, line 1; a memo from E.S. Tucker to W.B. Papageorge, December 21, 1970 (both Monsanto, PCB results for hog's liver and fat samples).

http://www.chemicalindustryarchives.org/dirtysecrets/annistonindepth/wildlife.asp. Accessed: February 15, 2013.

Choi, A.L., Levy, J.I., Dockery, D.W., Ryan, L.M., Tolbert, P.E., Altshul, L.M., Korrick, S.A., 2006. Does living near a Superfund site contribute to higher polychlorinated biphenyl (PCB) exposure? Environ. Health Perspect. 114(7), 1092-1098.

DeCaprio, A.P., Johnson, G.W., Tarbell, A.M., Carpenter, D.O., Chiarenzelli, J.R., Morse, G.S., Santiago-Rivera, A.L., Schymura, M.J., Akwesasne Task Force on the Environment, 2005. Polychlorinated biphenyl (PCB) exposure assessment by multivariate statistical analysis of serum congener profiles in an adult Native American population. Environ Res. 98(3), 284-302.

EPA (U.S. Environmental Protection Agency), 1976. PCBs in the United States: Industrial use and environmental distribution. NTIS PB252012. U.S. Environmental Protection Agency, Office of Toxic Substances, Washington, DC.

EPA (U.S. Environmental Protection Agency), 2013. Anniston PCB Site. http://www.epa.gov/region4/superfund/sites/npl/alabama/anpcbstal.html. Accessed 06/14/2013.

FDA (Food and Drug Administration), 2012. Unavoidable contaminants in food for human consumption and food packaging material: tolerances for polychlorinated biphenyls (PCB's). Code of Federal Regulations. 21 CFR 109.30.

Gallo, M.V., Schell, L.M., DeCaprio, A.P., Jacobs, A., 2011. Levels of persistent organic pollutant and their predictors among young adults. Chemosphere 83(10), 1374-1382. 
Garabrant, D.H., Franzblau, A., Lepkowski, J., Gillespie, B.W., Adriaens, P., Demond, A., Hedgeman, E., Knutson, K., Zwica, L., Olson, K., Towey, T., Chen, Q., Hong, B., Chang, C.W., Lee, S.Y., Ward, B., Ladronka, K., Luksemburg, W., Maier, M., 2009. The University of Michigan Dioxin Exposure Study: predictors of human serum dioxin concentrations in Midland and Saginaw, Michigan. Environ. Health Perspect. 117(5), 818-824.

Goncharov, A., Bloom, M., Pavuk, M., Birman, I., Carpenter, D.O., 2010. Blood pressure and hypertension in relation to levels of serum polychlorinated biphenyls in residents of Anniston, Alabama. J. Hypertension 28(10), 2053-2060.

Goncharov, A., Pavuk, M., Foushee, H.R., Carpenter, D.O. for the Anniston Environmental Health Research Consortium, 2011. Blood pressure in relation to concentrations of PCB congeners and chlorinated pesticides. Environ. Health Perspect. 119(3), 319-325.

Grigsby, R.K., Thyer, B.A., Waller, R.J., Johnston Jr., G.A., 1999. Chalk eating in middle Georgia: a culture-bound syndrome of pica? South Med J. 92(2): 190-192.

Hansen, L., 2001. Identification of steady state and episodic PCB congeners from multiple pathway exposures, in: Robertson, L.H.L. (Ed.), PCBs. University Press of Kentucky, Lexington, KY., pp. 47-56.

Haque, R., Schmedding, D., 1976. Studies on the adsorption of selected polychlorinated biphenyl isomers on several surfaces. J. Environ. Sci. Health B11(2), 129-137.

Harrad, S., Ibarra, C., Robson, M., Melymuk, L., Zhang, X., Diamond, M., Douwes, J., 2009. Polychlorinated biphenyls in domestic dust from Canada, New Zealand, United Kingdom and United States: Implications for human exposure. Chemosphere 76(2), 232-238.

Horii, Y., Ohtsuka, N., Minomo, K., Nojiri, K., Kannan, K, Lam, P.K.S., Yamashita, N., 2011. Distribution, Characteristics, and Worldwide Inventory of Dioxins in Kaolin Ball Clays.

Environ. Sci. Technol. 45(17), 7517-7524.

Hornung, R.W., Reed, D.R., 1990. Estimation of average concentration in the presence of nondetectable values. App. Occup. Environ. Hyg. 5(1), 46-51.

Hovinga, M.E., Sowers, M., Humphrey, H.E., 1992. Historical changes in serum PCB and DDT levels in an environmentally-exposed cohort. Arch Environ Contam Toxicol. 22(4), 362-366.

Humblet, O., Williams, P.L., Korrick, S.A., Sergeyev, O., Emond, C., Birnbaum, L.S., Burns, J.S., Altshul, L., Patterson, D.G., Turner, W.E., Lee, M.M., Revich, B., Hauser, R. 2010. Predictors of serum dioxin, furan, and PCB concentrations among women from Chapaevsk, Russia. Environ. Sci. Technol. 44(14): 5633-5640. 
Humphrey, H.E., Budd, M.L., 1996. Michigan's fisheater cohorts: a prospective history of exposure. Toxicol. Ind. Health 12(3-4), 499-505.

Kreiss, K., Zack, M.M., Kimbrough, R.D., Needham, L.L., Smrek, A.L., Jones, B.T., 1981. Association of blood pressure and polychlorinated biphenyl levels. JAMA 245(24), 2505-2509.

Laden, F., Neas, L.M., Spiegelman, D., Hankinson, S.E., Willett, W.C., Ireland, K., Wolff, M.S., Hunter, D.J., 1999. Predictors of plasma concentrations of DDE and PCBs in a group of U.S. women. Environ. Health Perspect. 107(1), 75-81.

Lee, D.H., Lind, L., Jacobs Jr., D.R., Salihovic, S., van Bavel, B., Lind, P.M. 2012. Associations of persistent organic pollutants with abdominal obesity in the elderly: The Prospective Investigation of the Vasculature in Uppsala Seniors (PIVUS) study. Environ, Int. 40, 170-178.

Liebl, B., Schettgen, T., Kerscher, G., Broding, H.C., Otto, A., Angerer, J., Drexler, H., 2004. Evidence for increased internal exposure to lower chlorinated polychlorinated biphenyls (PCB) in pupils attending a contaminated school. Int. J Hyg. Environ. Health 207, 315-324.

Little, R.J.A., Rubin, D.B., 2002. Statistical Analysis with Missing Data, second ed. WileyInterscience, Hoboken, NJ.

Löffler, G., van Bavel, B., 2000. Potential pathways and exposure to explain the human body burden of organochlorine compounds: a multivariate statistical analysis of human monitoring in Würzburg, Germany. Chemosphere 40(9-11), 1075-1082.

Longnecker, M.P., Rogan, W.J., Lucier, G., 1997. The human health effects of DDT (dichlorodiphenyltrichloroethane) and PCBS (polychlorinated biphenyls) and an overview of organochlorines in public health. Annu. Rev. Public Health 18, 211-244.

Lorentz, W., 2005, June 22. U.S. Fish and Wildlife Service. Contaminated Sediments Technical Advisory Group (CSTAG) Stakeholders Meeting. Anniston PCB Site. Oxford, Alabama.

Love, D., 2007. My City Was Gone: One American Town's Toxic Secret, Its Angry Band of Locals, and a $\$ 700$ Million Day in Court. Harper Perennial Publishers.

Lovejoy, J.C., Champagne, C.M., de Jonge, L., Xie, H., Smith, S.R. 2008. Increased visceral fat and decreased energy expenditure during the menopausal transition. Int. J. Obes. (Lond), 32(6):949-958.

Nicholson, W.J., Landgrigan, P.J., 1994. Human health effects of polychlorinated biphenyls, in: Schecter, A. (Ed.), Dioxins and Health. Plenum Press, New York, pp. 487-534.

Nisbet, I.C., Sarofim, A.F., 1972. Rates and Routes of Transport of PCBs in the Environment. Environ. Health Perspect. 1, 21-38. 
Orloff K.G., Dearwent, S., Metcalf, S., Kathman, S., Turner, W., 2003. Human exposure to polychlorinated biphenyls in a residential community. Arch. Environ. Contam. Toxicol. 44, 125131.

Ouw, H.K., Simpson, G.R., Siyali, D.S., 1976. Use and health effects of Aroclor 1242, a polychlorinated biphenyl, in an electrical industry. Arch. Environ. Health 31(4), 189-194.

Patterson Jr., D.G., Wong, L.Y., Turner, W.E., Caudill, S.P., Dipietro, E.S., McClure, P.C., Cash, T.P., Osterloh, J.D., Pirkle, J.L., Sampson, E.J., Needham, L.L., 2009. Levels in the U.S. population of those persistent organic pollutants (2003-2004) included in the Stockholm Convention or in other long range transboundary air pollution agreements. Environ. Sci. Technol. 43(4), 1211-1218.

Pavuk, M., Olson, J.R., Sjödin, A., Bonner, M., Dearwent, S.M., Turner, W.J., Needham, L.L. for the Anniston Environmental Health Research Consortium, 2009. Assessment of human exposure to PCBs in the Anniston Community Health Survey. Organohalogen Compds. 71, 1066-1069.

Pavuk, M., Olson, J.R., Sjödin, A., Wolff, P., Turner, W.E., Shelton, C., Dutton, N.D., Bartell, S., for the Anniston Environmental Health Research Consortium, 2014. Serum concentrations of polychlorinated biphenyls (PCBs) in participants of the Anniston Community Health Survey. Sci. Total Env. 473-474, 286-297.

Phillips, D.L., Pirkle, J.L., Burse, V.W., Bernert Jr., J.T., Henderson, L.O., Needham, L.L., 1989. Chlorinated hydrocarbon levels in human serum: effects of fasting and feeding. Arch. Environ. Contam. Toxicol. 18, 495-500.

Reeuwijk, N.M., Talidda, A., Malisch, R., Kotz, A., Tritscher, A., Fiedler, H., Zeilmaker, M.J., Kooijman, M., Wienk, K.J.H., Traag, W.A., Hoogenboom, R.L.A.P., 2013. Dioxins (polychlorinated dibenzo-p-dioxins and polychlorinated dibenzo-furans) in traditional clay products used during pregnancy. Chemosphere 90(5), 1678-1685.

Rogan, W.J., Gladen, B.C., McKinney, J.D., Carreras, N., Hardy, P., Thullen, J., Tingelstad, J., Tully, M., 1986. Polychlorinated biphenyls (PCBs) and dichlorodiphenyl dichloroethene (DDE) in human milk: effects of maternal factors and previous lactation. Am. J. Public Health 76(2), 172-177.

Roos, V., Rönn, M., Salihovic, S., Lind, L., van Bavel, B., Kullberg, J., Johansson, L., Ahlström, H., Lind, P.M. 2013. Circulating levels of persistent organic pollutants in relation to visceral and subcutaneous adipose tissue by abdominal MRI. Obesity (Silver Spring) 21(2), 413-418.

Schecter, A., Cramer, P., Boggess, K., Stanley, J., Päpke, O., Olson, J., Silver, A., Schmitz, M., 2001. Intake of dioxins and related compounds from food in the US population. J. Toxicol. Environ. Health A 63, 101-118. 
Schisterman, E.F., Whitcomb, B.W., Louis G.M.B., Louis T.A., 2005. Lipid adjustment in the analysis of environmental contaminants and human health risks. Environ. Health Perspect. 113, 853-857.

Schwartz, P.M., Jacobson, S.W., Fein, G., Jacobson, J.L., Price, H.A., 1983. Lake Michigan fish consumption as a source of polychlorinated biphenyls in human cord serum, maternal serum, and milk. Am. J. Public Health 73(3), 293-296.

Silverstone, A.E., Rosenbaum, P.F., Weinstock, R.S., Bartell, S.M., Foushee, H.R., Shelton, C., Pavuk, M., 2012. Polychlorinated Biphenyl (PCB) Exposure and Diabetes: Results from the Anniston Community Health Survey. Environ. Health Perspect. 120(5), 727-732.

Sjödin, A., Hagmar, L., Klasson-Wehler, E., Björk, J., Bergman, A., 2000. Influence of the consumption of fatty Baltic Sea fish on plasma levels of halogenated environmental contaminants in Latvian and Swedish men. Environ. Health Perspect. 108(11), 1035-1041.

Sjödin, A., Jones, R.S., Lapeza, C.R., Focant, J.F., McGahee, E.E., Patterson, D.G., 2004. Semiautomated high-throughput extraction and cleanup method for the measurement of polybrominated diphenyl ethers, polybrominated biphenyls, and polychlorinated biphenyls in human serum. Anal. Chem. 76, 1921-1927.

Startin, J.R., 1994. Dioxins in food, in: Schecter, A. (Ed.), Dioxins and Health. Plenum Press, New York, pp. 115-137.

Sweeney, A.M., Symanski, E., Burau, K.D., Kim, Y.J., Humphrey, H.E., Smithci, M.A., 2001. Changes in serum PBB and PCB levels over time among women of varying ages at exposure. Environ Res. 86(2), 128-139.

Tee, P.G., Sweeney, A.M., Symanski, E., Gardiner, J.C., Gasior, D.M., Schantz, S.L., 2003. A longitudinal examination of factors related to changes in serum polychlorinated biphenyl levels. Environ. Health Perspect. 111(5), 702-707.

Vermeer, D.E., Frate, D.A., 1979. Geophagia in rural Mississippi: environmental and cultural contexts and nutritional implications. Am. J. Clin. Nutr. 32(10), 212902135.

Wang, W., Huang, M.J., Zheng, J.S., Cheung, K.C., Wong, M.H., in press (2013). Exposure assessment and distribution of polychlorinated biphenyls (PCBs) contained in indoor and outdoor dusts and the impacts of particle size and bioaccessibility. Sci. Total Env. 463-464, 1201-1209.

Warner, J., Osuch, J.R., Karmaus, W., Landgraf, J.R., Taffe, B., O'Keefe, M., Mikucki, D., Haan, P. 2012. Common classification schemes for PCB congeners and the gene expression of CYP17, CYP19, ESR1 and ESR2. Sci. Total. Environ. 414: 81-89. 
Weintraub, M., Birnbaum, L.S., 2008. Catfish consumption as a contributor to elevated PCB levels in a non-Hispanic black subpopulation. Environ. Res. 107(3), 412-417.

Wolff, M.S., Fischbein, A., Thornton, J., Rice, C., Lilis, R., Selikoff, I.J., 1982. Body burden of polychlorinated biphenyls among persons employed in capacitor manufacturing. Int. Arch.

Occup. Environ. Health 49(3-4), 199-208.

Wolff, M.S., 1985. Occupational exposure to polychlorinated biphenyls (PCBs). Environ. Health Perspect. 60, 133-13. 